\title{
CEREBROSPINAL FLUID DRAINAGE DEVICES: EXPERIMENTAL CARACTERIZATION
}

\author{
C. Bim ${ }^{\mathrm{a}}$, ABSTRACT \\ M. Pinotti ${ }^{\mathbf{a}}$, \\ J. R. Camilob, \\ A. L. Maset ${ }^{\mathbf{b}}$, \\ Hydrocephalus is a pathophysiology due to the excess of cerebrospinal fluid \\ in the brain ventricles and it can be caused by congenital defects, brain \\ abnormalities, tumors, inflammations, infections, intracranial hemorrhage \\ and others. Hydrocephalus can be followed by significant rise of \\ intraventricular pressure due to the excess of production of cerebrospinal \\ fluid over the absorption, resulting in a weakening of intellectual functions, \\ S. S. Mansur \\ and E. D. R Vieira ${ }^{c}$ \\ serious neurological damage (decreased movement, sensation and \\ functions), critical physical disabilities and even death. A procedure for \\ treatment involves the placement of a ventricular catheter into the cerebral \\ ${ }^{\mathrm{a}}$ UFMG - Universidade Fed. de Minas Gerais \\ Av. Antonio Carlos, 6627, \\ Belo Horizonte, Minas Gerais \\ ${ }^{\mathrm{b}}$ Ventura Biomédica \\ Av. Francisco Chagas de Oliveira, 1100, \\ São José do Rio Preto, São Paulo \\ ${ }^{\mathrm{c}}$ UNESP - Ilha Solteira - \\ Av. Brasil Centro, 56, \\ Ilha Solteira, São Paulo \\ Received: October 25, 2013 \\ Revised: November 20, 2013 \\ Accepted: December 30, 2013 \\ ventricles to divert/drain the cerebrospinal fluid flow to a bag outside of the \\ patient body - provisory treatment known as external ventricular drainage \\ (EVD). Another option is the permanent treatment, internal ventricular \\ drainage (IVD), promoting the cerebrospinal fluid drainage to other body \\ cavity, being more commonly the abdominal cavity. In both cases, EVD \\ and IVD, it is necessary to use of some type of neurological valve in order \\ to control the flow of cerebrospinal fluid. In the present work is proposed \\ an experimental procedure to test the hydrodynamic behavior of a complete \\ drainage system, or parts of them, in order to verify its performance when \\ subjected to pressure gradients found in the human body. Results show that \\ the method is well adapted to quantify the pressure drop in neurological \\ systems. \\ Keywords: Hydrocephalus, Cerebrospinal fluid, Ventricular drainage.
}

\section{NOMENCLATURE}

D pipe diameter, $\mathrm{m}$

f friction factor for pipes

$\mathrm{f}_{\exp } \quad$ experimental friction factor

$\mathrm{f}_{\mathrm{L}} \quad$ Hagen-Poiseuille friction factor

g local gravitational acceleration, $\mathrm{m} / \mathrm{s}^{2}$

$\mathrm{K}_{\mathrm{e}} \quad$ loss pressure coefficient for pipe entrance

$\mathrm{K}_{\mathrm{v}} \quad$ loss pressure coefficient for valves

$\mathrm{L} \quad$ pipe lenght, $\mathrm{m}$

Re Reynolds number

$\overline{\mathrm{V}}$ mean flow velocity, $\mathrm{m} / \mathrm{s}$

$\mathrm{z} \quad$ vertical coordinate in upward, $\mathrm{m}$

\section{Greek symbols}

$\alpha \quad$ kinetic energy coefficient,

$\rho \quad$ water density, $\mathrm{kg} / \mathrm{m}^{3}$,

$\mu \quad$ water viscosity, $\mathrm{N} \mathrm{s} / \mathrm{m}^{2}$,

\section{INTRODUCTION}

Cerebrospinal fluid, also known as CSF, is an aqueous colorless odorless fluid, with a low concentration of cells and proteins. According to Adam et al. (2001), the cerebrospinal fluid fills all internal and external spaces of the brain showing a stable ionic composition. About $20 \%$ of all CSF of the body is found in ventricles - intracerebral spaces - and in foramens - very small channels connecting the ventricles -, while the other $80 \%$ is located in areas outside the brain, in the brain surroundings and in the spinal cord, as depicted in Figure 1.

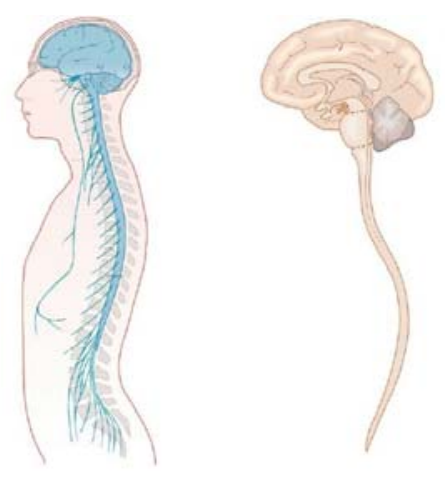

Figure 1. Structure of the brain and spinal cord in the human body (Adapted from Waxman, 2010).

According to Adam et al. (2001) and Irani (2009), the main functions of the cerebrospinal fluid are to protect the brain and the spinal cord from mechanical shocks, and to regulate the ionic 
composition. CFS also plays an important role in the biological protection of the nervous system, distributing nutrients, proteins and agents of defense against infections and carries away metabolites residues.

Healthy adult presents about $150 \mathrm{ml}$ of CSF total volume flowing throughout its body and a continuous daily production rate between 400 and $500 \mathrm{ml}$ (Carlotti Jr, et al., 1998).

In accord to Camilo (2005), the cerebrospinal fluid is continually produced by a tissue called the choroid plexus situated in the lateral cerebral ventricles. Most of the cerebrospinal fluid is produced by first and second ventricle (called lateral ventricles - one in each hemisphere of the brain). The Fig. 2 illustrates the path of the cerebrospinal fluid. After being produced and fill the lateral ventricles, CFS is conducted to the third ventricle through a small aperture called foramen of Monro (a very small brain orifice). Thus, the third ventricle (single cavity situated in the center of the brain) is filled with liquid deposited and joins a small volume produced locally. Continuing its path, CFS flows into the aqueduct of Sylvius to the fourth ventricle (small cavity on the back of the brain). The fourth ventricle also has a very low account of choroid plexus tissues. Donwstream the fourth ventricle, all CFS produced in the brain is drained out through Lushka and Magendie foramens. Following, the CSF bathes the outer surface of the brain (with its several cavities) and spinal cord. After this long way, from the interior to the surface of the brain, the fluid is absorbed in small structures called arachnoid granulations (venous absorption).

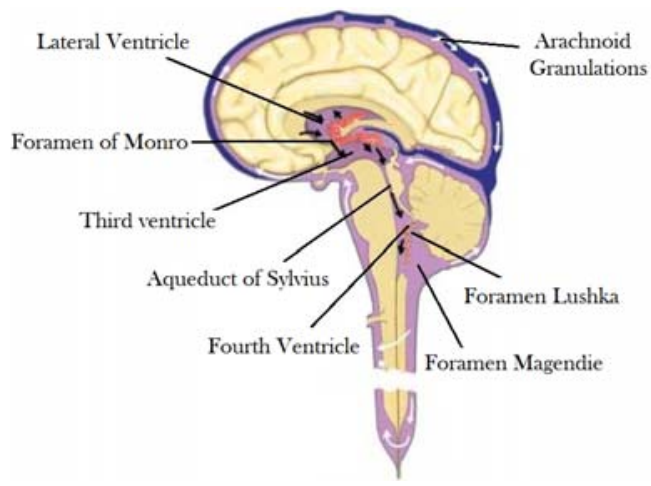

Figure 2. Path of Cerebrospinal Fluid (Adapted from Rohkamm, 2004).

Normally, there is a natural balance between production and absorption of cerebrospinal fluid. In other words, the same volume which is produced in one part of the brain should match that is absorbed elsewhere. The hydrocephalus occurs when there is a disturbance in cerebral spinal dynamics (lock in your flows, decreased ability to absorb or overproduction) implying, in general, the accumulation of CSF in the ventricles. The hydrocephalus can be followed by significant rise of intracerebral pressure (ICP) due to the excess of cerebrospinal fluid in brain ventricles (Souza et al., 2007).

Hydrocephalus is a pathophisiology that affects both adults and childrens, and it can be caused by congenital malformations, brain anomalies, tumors, inflammations, infections, encephalitis, intracranial hemorrhages, subdural or epidural hematoma, abscess, traumatisms and others (Camilo, 2005).

The hydrocephalus may result in a weakening of intellectual functions, serious neurological damage (decreased movement, sensation and functions), critical physical disabilities and even death.

After the diagnosis of hydrocephalus, there are some surgical options for treatment. One of those procedures involves the placement of a ventricular catheter into the cerebral ventricles to divert/drain the cerebrospinal fluid flow to a bag outside of the body - provisory treatment known as external ventricular drainage (EVD). Another option is the permanent treatment, internal ventricular drainage (IVD) that promotes the cerebrospinal fluid drainage to another body cavity, being more commonly the abdominal cavity. In both cases, EVD and IVD, it is necessary to use a neurological valve to control the flow of cerebrospinal fluid in acceptable levels. An excessive drainage (or over drainage) can occur after shunting, but it must be avoided because only a few seconds in this adverse condition can produce an irreversible cerebral damage in the patient (Kremeer et al. 1994).

According to Sood, et al. (1999), since 1960, when the shunt (drainage procedure of cerebrospinal fluid) was created, the mortality rates by hydrocephalus suffered a decline of $54 \%$ to only $5 \%$, while the loss of brain skills of patients decreased from $62 \%$ to $30 \%$.

In the present work a test procedure is proposed for hydrodynamic characterization of neurological valves. Additionally, a study of a one-way neurological valve, known as membrane valve, designed to work outside the body - external ventricular drainage - is made. Since the hydraulic resistance influences directly the valve performance, it is necessary to study its system behavior as submitted to different pressure gradients. In this way, it is possible to determine the pressure loss coefficients of the valve, in order to evaluate its performance in a possible application as drainage system.

\section{EXPERIMENTAL APPARATUS}

There are an extensive number of publications available in technical literature showing several experimental apparatus for testing neurological valves, from very sophisticated to simple conceptions that provide reliable data. Drake and SainteRose (1994) show several conceptions of devices to performing test in valves shunts utilizing infusion pumps and electronic measurements of pressure and 
volumetric flow. In many other works, the construction details of test devices of valves for CSF drainage are not available, as examples, Horton and Pollay (1990), Sood et al. (1998) and Kremeer et al. (1994). Infusion pumps are precise pumps of positive displacement. A positive displacement devices remain constant the flow rate. Positive displacement infusion pumps show an extensive utilization in neurological valves tests, but the ICP produced by cerebral ventricles produces a CSF flow dynamics more close than a non positive displacement pump than a positive displacement pump. Mariotte bottle is an ingenious device which remains the exit pressure constant regardless of the level of the liquid in the delivery vessel. Utilization of Mariotte siphons is very adequate for testing neurological valves since the inlet pressure remain constant during all the runtime.

The Fig. 3 depicts a simplified sketch of the experimental apparatus utilized in this work, which consists of: a Mariotte bottle (A) made in Plexiglas, adequately placed on a digital balance (B) - Marte balance model AS 2000 - with $\pm 0.005 \mathrm{~g}$ of accuracy and measurement up to $2000 \mathrm{~g}$. An electronic digital chronometer made by Cronobio model SW2018 with an uncertain of $\pm 0.01 \mathrm{~s}$ directly coupled in the balance permits to determine the instantaneous mass flow rate. The liquid inside the Mariotte bottle is continuously drained to the reservoir (D) through a stainless steel tube with $2.5 \mathrm{~mm}$ of internal diameter and $4.0 \mathrm{~m}$ of length, where the valve under study $(\mathrm{F})$ is located in one of its ends. Throughout the process of data acquisition the temperature of the fluid is continually measured by means of a digital thermometer (E) Minipa MT 40IA with $\pm 0.5^{\circ} \mathrm{C}$ of dial indicator uncertain with a range from $50^{\circ} \mathrm{C}$ to $750^{\circ} \mathrm{C}$. A constant flow rate is produced by using the Mariotte bottle, since the exit pressure not changes, regardless the level variations of liquid inside the bottle.

Experimental uncertainties have been properly estimated, in order to provide reliable data. The balance has been evaluated using ABNT standard mass. Stainless steel tube used in this work has been produced for pharmaceutical industry for hypodermic needles production.

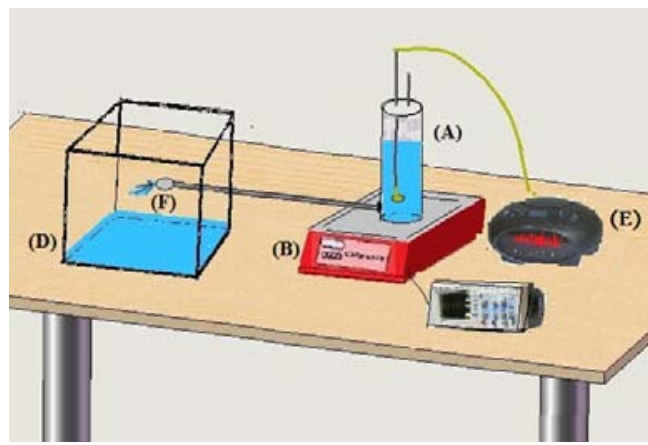

Figure 3. Schematic of experimental apparatus (Bim et al., 2010).

\section{RESULTS}

Initially tests were performed out using several pressure gradients equivalent to (ICP), ranging from 40 to $240 \mathrm{mmH}_{2} \mathrm{O}$, without the valve. Thus, it was measured the pressure loss of the rigid circular pipe and, consequently, the friction factor $\left(f_{\exp }\right)$ for the tube can be experimentally determined, using the energy equation for pressure loss of pipes.

$$
g(\Delta z)-\frac{\bar{V}^{2}}{2}=f_{\exp } \frac{L}{D} \frac{\bar{V}^{2}}{2}+K_{e} \frac{\overline{V^{2}}}{2}
$$

For laminar flow, friction factor of pipes $\left(f_{L}\right)$ can be calculated by Hagen-Poiseuille formulation for a fully developed velocity profile in laminar steady flow of a Newtonian fluid.

$$
f_{L}=\frac{64}{\operatorname{Re}}=\frac{64 \mu}{\rho \bar{V} D}
$$

The results are shown in Fig. 4, where the red line represents the friction factor of the tube experimentally determined $\left(\mathrm{f}_{\exp }\right)$ and the blue line represents the friction factor in accord to HagenPoiseuille formulation - Eq. (2). The graphic shows a significant difference between the friction factors obtained by means of the two equations. This is due to the fact of Eq. (2) be only valid for steady laminar flow (Reynolds numbers less than 2100) of Newtonian fluids having a fully developed velocity profile (Fox and McDonald, 1995). Thus, it was chosen to work with the experimental friction factor $\left(f_{\text {exp }}\right)$.

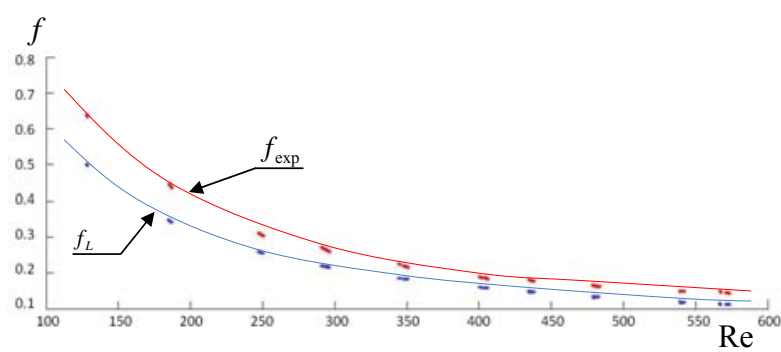

Figure 4. Friction factor of a pipe in function of Re.

Once determined the coefficient of friction of the tube $\left(f_{\text {exp }}\right)$, a valve neurological can be coupled in the free end of the stainless steel tube. In this case, Eq. (1) must be rewritten in order to consider the pressure drop produced by the neurological valve.

$$
g(\Delta z)-\frac{\bar{V}^{2}}{2}=f_{\exp } \frac{L}{D} \frac{\bar{V}^{2}}{2}+K_{e} \frac{\bar{V}^{2}}{2}+K_{V} \frac{\bar{V}^{2}}{2}
$$

Results for pressure gradients from 40 up to $240 \mathrm{mmH}_{2} \mathrm{O}$ for a typical membrane valve is shown in Fig. 5. 


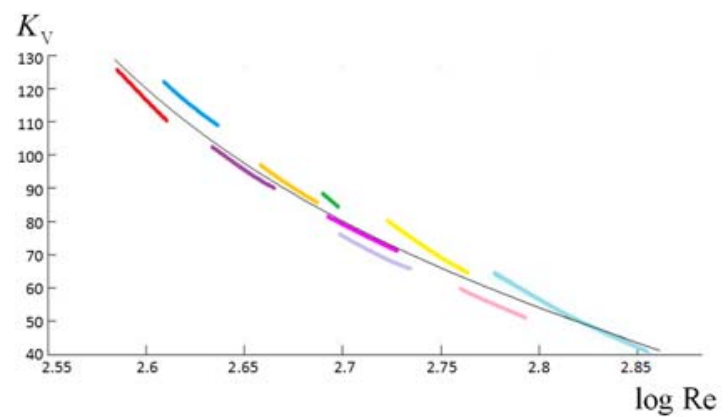

Figure 5. Loss of pressure coefficient for a valve.

\section{CONCLUSIONS}

Humans are estimated to produce continually about $0.5 \mathrm{ml} / \mathrm{kg}$ per hour, or approximately $500 \mathrm{ml}$ of CSF each day. A discrepancy in CSF production and absorption cumulates an excess of fluid in the brain. Elevated levels of CSF are associated with traumatic brain injury, meninge infections (meningitis) and a pediatric disease known as hydrocephalus. In all of these cases, an increase fluid pressure (intracranial pressure) can be observed resulting in permanent brain injury and death.

If diagnosis of hydrocephalus has been obtained there are rarely options other than surgery for treatment. Most surgeons use various types of systems called shunts to channel the fluid from the ventricles to other sites in the body such as the abdominal cavity (internal shunts). CSF drainage can be realized also for an external reservoir (external shunts).

In 1999, Aschoff et al. (1999) show 127 different types of neurological valves commercially available, conceived since 1949, and more than other 70 models in different developing stages. All internal and external drainage systems (and each individual component) could be intensively tested in order to determine its hydrodynamic behavior. In this work, a new procedure for neurological valve test has been proposed, allowing comparing hydraulic characteristics of shunt parts or of a complete system. The individual measurement of pressure drop in all the parts of a drainage shunt is very important for a detailed engineering project of a neurological valve.

\section{ACKNOWLEDGEMENTS}

This work has been developed by FAPESP, CNPq and FUNDUNESP grants. VENTURA BIOMÉDICA supplied all materials to manufacturing the test apparatus and provides funding for this work.

\section{REFERENCES}

Adam, P., Táborský, L., Sobek, O., Hildebrand, T., Kelbich, P., Prucha, M., and Hyánek, J., 2001, Cerebrospinal fluid, Academic Press.
Aschoff, A., Kremer, P., Hashemi, B., and Kunze, S., 1999, The Scientific History of Hydrocephalus and its Treatment, Neurosurgical Review, Vol. 22, pp. 67-93.

Bim, C., Mansur, S. S., Vieira, E. D. R., Camilo, J. R., and Maset, A. L., 2011, Study about Duck Bill Check Valves in Neurological Applications, in: COBEM 2011 - 21th Brazilian Congress of Mechanical Engineering, Natal, RN.

Camilo, J. R, 2005, Simulação Hidrodinâmica e Caracterização Experimental de Mecanismos Antisifão em Sistemas de Drenagem Externa de Líquido Cefalorraquidiano, Master Thesis, Universidade Estadual de São Paulo - UNESP, Ilha Solteira, SP. (in Portuguese)

Carlotti Jr, C. G., Colli, B. O., and Dias, L. A. A., 1998, Hipertensão Intracraniana, in: Simpósio Medicina Intensiva, Ribeirão Preto, SP. (in Portuguese)

Drake, J. M., and Sainte-Rose, C., 1994, The Shunt book, Blackwell Science, 228 p.

Fox, R. W., McDonald, A. T., and Pritchard, P. J., 1995, Introduction to Fluid Mechanics, 6th Edition, John Wiley.

Horton, H., and Pollay, M. P., 1990, Fluid Flow Performance of a New Siphon-control Device for Ventricular Shunts, Journal of Neurosurgical, Vol. 72, pp. $926-932$

Irani, D. N., 2009, Cerebrospinal Fluid in Clinical Practice, Elsevier.

Kremeer, P., Aschoff, A., and Kunze, S., 1994, Risks of Using Siphon-Reducting Devices, Child's Nervous System, Vol. 10, pp. 231-235.

Rohkamm, R., 2004, Color Atlas of Neurology, Thieme.

Sood, S., Canady, A. I., and Ham, S. D., 1999, Adjustable Antisiphon Shunt, Child's Nervous System, Vol. 15, pp. 246-249.

Souza, H., Doutel, F., Borge, C. A., Azevedo, R. G., Walter, R., and Ribeiro, C. H., 2007, Hidrocefalia Aguda Essencial, Arquivos Brasileiros de Neurocirurgia, Vol. 26, No. 2, pp. 53-59. (in Portuguese)

Waxman, S. B., 2010, Clinical Neuroanatomy, 26th Edition, McGraw-Hill. 